九州大学学術情報リポジトリ

Kyushu University Institutional Repository

\title{
A Review on Tensile Behavior of Different Kinds of Fiber Reinforced Concrete
}

Chakraborty, Rohit

Department of Civil Engineering, Ahsanullah University of Science and Technology

Paul, Tonmoy

Department of Civil Engineering, Ahsanullah University of Science and Technology

Abu Bakor Siddik Ornob

Department of Civil Engineering, Ahsanullah University of Science and Technology

https://doi.org/10.5109/4102495

出版情報: Proceedings of International Exchange and Innovation Conference on Engineering \& Sciences (IEICES). 6, pp. 231-237, 2020-10-22. Interdisciplinary Graduate School of Engineering Sciences, Kyushu University

バージョン：

権利関係 : 


\title{
A Review on Tensile Behavior of Different Kinds of Fiber Reinforced Concrete
}

\author{
Rohit Chakraborty ${ }^{1}$, Tonmoy Paul ${ }^{2}$, Abu Bakor Siddik Ornob ${ }^{3}$ \\ 1,2,3 Department of Civil Engineering, Ahsanullah University of Science and Technology, Bangladesh \\ Corresponding author email: rohitck98@gmail.com
}

\begin{abstract}
With the development of science and technology of material in civil engineering, concrete has been the mostly used building material worldwide. Concrete, best known for its high compressive strength also has defects in some of its mechanical behaviors likely low tensile performance, bad toughness, low anti-cracking performance and so on. Inclusion of fibers in concrete can significantly improve its tensile performance. Researches and development efforts are being made to use different types of natural, metallic and synthetic fibers as reinforcement to fiber reinforced concrete (FRC) for better tensile performance. Despite such interest to use fibers in concrete structures, some doubts still remain regarding the influence of fibers on the tensile properties of concrete. The aim of this review paper is to provide a consolidated conclusion made from numerous researches to date on the tensile behavior of FRC, which have been conducted using different kind of fibers.
\end{abstract}

Keywords: Building material; Concrete technology; Fiber Reinforced Concrete.

\section{INTRODUCTION}

Concrete, the most widely used construction material all over the world, is composed of cement, fine aggregates and coarse aggregates mixed with water which causes it to harden with time. Timber and steel are also used as building material as an alternative to concrete. Rilya Rumbayan and Meita Rumbayan [1] studied the use of local coconut timber waste as an alternative building material. Apart from its excellent resistance to water, availability, low cost and durability, the most important property of concrete is its high compressive strength [3-4]. At the same time, it is also a brittle material, with low tensile strength and strain capacities, low anti-cracking performance and bad toughness. [5-6]. As, cement is a chemical compound, these flaws can make concrete susceptible to attack by aggressive environments and to use under severe conditions to a larger extent [2]. To this context, the Fiber Reinforced Concrete (FRC) is introduced creating a remarkable dimension in concrete technology. Many researchers have done a lot of investigations using fibers as a reinforcement material for concrete.

The cracking of concrete occurs mainly due to tension. Hence, the measurement of tensile strength is compulsory to determine the load at which the concrete members may crack. Improvement in tensile strength of concrete can be achieved by incorporating fibers into the cement based materials. As one of the most significant areas of research, this review paper primarily focuses to enhance the understanding of the tensile behavior of fiber reinforced concrete. This understanding is necessary in order to open the door for its future potential use in the field.

\section{CLASSIFICATION OF FIBERS}

Fibers are categorized as natural, synthetic and metallic in this paper. Natural fibers used as reinforcement material in concrete are basically extracted from plants such as jute, bamboo, brown coconut and many more. Basalt is a type of inorganic natural fiber extracted from basalt rocks. Researchers have conducted a lot of studies using natural fibers due to its economic and eco-friendly characteristics. Mohammad Zakaria et al. [9] stated that use of jute to reinforce concrete strength will prevent the application of polymer which is environmentally hazardous. Synthetic fibers are artificial fibers produced through chemical synthesis. Glass, Polypropylene are mostly used synthetic fibers to reinforce concrete. Glass fiber is a material which is made from extremely fine fibers of glass based on silica [7]. Based on chemical composition, glass fibers can be of different types. Glass fibers are available in different shapes, forms such as continuous fiber, roving, staple fiber, and chopped strand mat etc. [8]. Metallic fibers are mostly consisting of steel and aluminum fibers. Metallic fibers have little or no chance having either bacterial attack or fungal attack in wet conditions unlike natural fibers extracted from plants and vegetables.

\subsection{Natural Fiber Reinforced Concrete}

Jute was once known to be the golden fiber of Bangladesh. Its application here was rather traditional than technical and thus it was necessary to explore the efficacious usage of this native fiber according to many past authors. M.A. Mansur and M.A. Aziz [26] investigated the mechanical properties of cement paste mortar with three different mix ratio of cement and sand reinforced with jute fibers. The results showed a maximum increase of $97 \%$ in tensile strength for the jute fiber reinforced cement paste comparing control specimens. On the contrary, Mohammad Zakaria [9] conducted experiments on two different mix ratios of jute fiber reinforces concrete composites. As, it seems difficult to measure the direct tension. They conducted split tensile strength tests on cylindrical specimens according to test method ASTM C 496/M496 for determining the tensile strength of concrete. They reported shorter jute with lower content showed better results than longer fibers with more amount of 
concrete reinforcement as they are properly distributed and resist the cracking of cylinder against tensile load. Mohammad Zakaria et.al [10] used the same concrete specification and variation of fibers but investigated both jute fiber reinforced concrete and jute yarn reinforced concrete. It was observed that small fibers significantly enhance the tensile. After analyzing the concrete specimens, they reported the jute yarn provides better tensile strength than jute fiber as jute fiber creates more void spaces and causes "balling" formation in concrete mortar. Kavitha S. et. al. [11] used fiber of $1.156 \mathrm{~mm}$ diameter of aspect ratio 40 but made different use of fiber content $(0,0.5,0.75,1,1.25 \%)$ for finding out the optimum fiber content. The results of the splitting tensile test showed that the strength of the concrete increased $79.10 \%$ in 28 days for $1 \%$ fiber inclusion. Coconut fiber possesses significant toughness amongst natural fiber. That's why many authors studied the coconut fiber as a reinforcement in concrete. Ali et. al. investigated [12] the combination of different lengths of $2.5,5$ and $7.5 \mathrm{~cm}$ coconut fiber with the fiber content of $1 \%, 2 \%, 3 \%$ and $5 \%$ by cements mass in the concrete. The splitting tensile test on cylindrical specimen showed that for $1 \%$ fiber content, the tensile strength increased for every length of fiber. Chaichannawatik et. al. [23] conducted experiment on sisal and glass fiber reinforced concrete. The length and diameter of sisal fiber were $45-50 \mathrm{~mm}$ and $0.25 \mathrm{~mm} .6 \mathrm{~kg} / \mathrm{m}^{3}$ fiber was mixed in the normal strength concrete. The splitting tensile strength test indicated that sisal fiber increased the strength $10 \%$ compared to plain concrete.

A summary of the tensile properties of concrete reinforced with natural fibers provided in Table 1.

Table 1. Summarized data on Tensile properties of Natural Fiber Reinforced Concrete

\begin{tabular}{|c|c|c|c|c|c|c|}
\hline \multicolumn{5}{|c|}{ Fiber } & \multirow[t]{2}{*}{ "Tensile Properties (Effectiveness \%) } & \multirow[t]{2}{*}{ Reference } \\
\hline Name & $\begin{array}{c}\text { Length } \\
(\mathrm{mm})\end{array}$ & $\begin{array}{l}\text { Diameter } \\
(\mathbf{m m})\end{array}$ & $\mathrm{V} \%$ & $\begin{array}{l}\text { Wt. } \\
\text { (if) }\end{array}$ & & \\
\hline Bamboo & 46.24 & 1.156 & 1 & & $\begin{array}{l}\text { Splitting Tensile Strength }=4.8 \mathrm{MPa} \\
(+79.1 \%)\end{array}$ & {$[11]$} \\
\hline Jute & 18 & & 2 & & Tensile Strength $=2.36 \mathrm{~N} / \mathrm{mm}^{2}(+96.67 \%)$ & {$[26]$} \\
\hline Jute & 15 & & 0.10 & $\begin{array}{c}15.50 \\
\mathrm{gm}\end{array}$ & Tensile Strength $=(+35 \%)$ & [9] \\
\hline $\begin{array}{l}\text { Jute } \\
\text { yarn }\end{array}$ & 10 & & 0.10 & & Tensile Strength $=(+38 \%)$ & {$[10]$} \\
\hline $\begin{array}{l}\text { Brown } \\
\text { Coconut }\end{array}$ & 75 & 0.25 & 1 & & $\begin{array}{l}\text { Splitting Tensile Strength }=4.27 \mathrm{MPa} \\
(+11 \%)\end{array}$ & [12] \\
\hline
\end{tabular}

\subsection{Metallic fiber reinforced concrete}

Steel fiber enhance the concrete strength providing high elastic modulus and stiffness. Jun Zhao et. al [27] investigated the effect of steel fiber volume fraction and stirrup ratio on the shear behavior of reinforced concrete beams. They also analyzed the tensile concrete strain and diagonal crack width. The results showed increase in volume fraction increases the tensile strength of test reinforced concrete beams, but the stirrup ratio has no effect on it. It was observed that after adding steel fiber in the beam, the cracking load of the diagonal section and degree of concrete bearing in tension has increased, the widening speed of the diagonal crack at the web of the beam reduced. However, the extension of the crack of steel fiber reinforced beam concrete cannot be controlled. They also reported the combined effect of steel fibers stirrups further prevent the expansion and extension of the diagonal crack at the web. Y.K. Sabapathy et. al [28] studied the mechanical strength properties of aluminum fiber reinforced concrete. The results showed increase in fiber volume fraction increases the splitting tensile strength for every grade of concrete. In this study they used strength prediction equation to compare the experimental value with predicted value of splitting tensile strength. It was observed that for every specimen tested the experimental value was higher than the predicted value but was accurate to a considerable extent. The maximum absolute percentage error between the experimental and predicated value was only $8.73 \%$ and the minimum value was only $0.18 \%$. Yoo et. al. [13] studied the effect of corrosion of steel fiber which was used as reinforcing material on the tensile behavior of Ultra-High-Performance FiberReinforced Concrete (UHPFRC). From the result it was observed that only $\mathrm{C} 06 \mathrm{U}$ fiber which is an unwashed fiber of $6 \%$ provided corrosion degree, showed the only increment in the tensile strength value. Increment in the strain capacity was also highest for C06U fiber. Compared to washed corroded steel fiber, better tensile performance of UHPFRC was observed with unwashed corroded steel fiber. Kushartomo et. al. [14] experimented the mechanical strength behaviors such as compressive strength, splitting tensile strength and flexural 
strength of Reactive Powder Concrete (RPC) using steel fibers. The results indicated significant increment in splitting tensile strength with the addition of steel fibers up to an optimum level which is $1.5 \%$ volume fraction of steel fibers. Density of the concrete mixture increased as the volume of fiber content increased. Significant development on the crack preventing capacity of RPC caused by hydration, creep and shrinkage was observed as well when it was reinforced using steel fibers. Shivakumar et. al. [15] carried out an investigation on the mechanical properties of high strength concrete reinforced with metallic fiber and non-metallic fiber. Results from this experiment showed that, among all the non-hybrid and hybrid fiber combinations, only use of non-hybrid steel fibers in $0.5 \%$ volume fraction with high strength concrete mixture gives the best result in splitting tensile strength test. Aziminezhad et. al. [16] showed that steel fiber provides more strength and energy absorption than the glass fiber and polypropylene fiber in three-point bending test. The results showed that the concrete with steel fiber possessed highest peak load (3.53 $\mathrm{KN}$ ) at $1.5 \%$ fiber content comparing to glass fiber, polypropylene fiber and control concrete. Algburi et. al. [17] investigated the influence of steel fiber and glass fiber on the special type of high-performance reactive powder concrete. They prepared the RPC using $1.5 \%$ steel fiber $(13 \mathrm{~mm}$ long with $0.2 \mathrm{~mm}$ diameter) by volume and densified silica fume as additional cementitious material. The results of the indirect tensile strength showed that the steel fiber reinforced reactive powder concrete (SFR-RPC) gained $30 \%$ more strength than the non-fibrous reactive powder concrete (NF-RPC).

A summary of the tensile properties of concrete reinforced with metallic fibers provided in Table 2.

Table 2. Summarized data on Tensile properties of Metallic Fibers

\begin{tabular}{|c|c|c|c|c|c|c|}
\hline \multicolumn{5}{|c|}{ Fiber } & \multirow{2}{*}{$\begin{array}{l}\text { Tensile Properties } \\
\text { (Effectiveness \%) }\end{array}$} & \multirow[t]{2}{*}{ Reference } \\
\hline Name & $\begin{array}{l}\text { Length } \\
(\mathrm{mm})\end{array}$ & $\begin{array}{l}\text { Diameter } \\
(\mathbf{m m})\end{array}$ & $\mathrm{V} \%$ & $\begin{array}{l}\text { Wt. } \\
\text { (if) }\end{array}$ & & \\
\hline Steel & 13 & 0.2 & 1.5 & & $\begin{array}{l}\text { Splitting Tensile strength }=9.9 \\
\mathrm{MPa}(+30.3 \%)\end{array}$ & [17] \\
\hline Steel & 12.5 & 0.18 & 1.5 & & $\begin{array}{l}\text { Tensile Load }=3.53 \mathrm{KN}(+ \\
75.81 \%)\end{array}$ & [16] \\
\hline Steel & 30 & 0.5 & 0.5 & 38.98 & Tensile Strength $=5.2 \mathrm{MPa}(+26.8)$ & [15] \\
\hline Steel Bar & 30 & 0.3 & $\begin{array}{c}\text { Corrosion } \\
\text { Degree: } 6 \\
\text { (unwashed) } \\
\text { No of } \\
\text { fibers per } \\
\text { unit area } \\
\left(\mathrm{ea} / \mathrm{cm}^{2}\right) \text { : } \\
26.7\end{array}$ & & $\begin{array}{l}\text { Tensile Strength }=19.4 \mathrm{MPa} \\
(+16.16)\end{array}$ & [13] \\
\hline Steel & $11-13$ & $0.12-0.13$ & 1.5 & & $12.414 \mathrm{MPa}(+90.98)$ & [14] \\
\hline Steel & 32.2 & 0.92 & 1.5 & & $\begin{array}{l}\text { Tensile Strength }=5.85 \mathrm{MPa} \\
(+57.26)\end{array}$ & [27] \\
\hline Aluminum & 50 & 0.96 & 2 & & $\begin{array}{l}\text { Tensile Strength }=3.6 \mathrm{MPa} \\
(+36.88)\end{array}$ & [28] \\
\hline
\end{tabular}

\subsection{Synthetic Fiber Reinforced Concrete}

S. Anandaraj et. al [29] investigated the structural distress in glass fiber reinforced concrete under loading and to aggressive environments. Additionally, they used marble dust and granite dust in the concrete mixture. The results were recorded in both 7 days and 28 days. The most effective splittensile strength improvement was found in the mix of $1 \%$ glass fiber and 20\% marble dust. Hanuma Kasagani and C.B.K Rao [18] studied the effects of graded fibers on stress strain behavior of glass fiber reinforced concrete in tension. They concluded tensile strain hardening increased with increase in fiber volume content and fiber length. The results showed short graded fibers improve tensile strength and long graded fibers improve deformation capacity. In this study, they analyzed theoretically to predict the tensile strength of composites where two equations were used. The first equation was called rule of mixture and the second equation was modified 
by introducing fiber dispersion coefficient in first equation. It was noted that the strength values from the second equation was closer to the experimental values. Y.K. Sabapathy et. al [28] used aluminum fibers in the study. It was observed that, the use of aluminum fibers increases the split tensile strength of the specimens as the pull-out resistance of this randomly oriented looped end fibers was adequate enough to resist any propagation of cracks. Unlike Hanuma Kasagani and C.B.K Rao [18] they developed strength prediction equations using regression analysis. The predicted values were close to the experimental values and from the theoretical analysis it was found that the optimum volume fraction to be adopted in construction practices is $0.77 \%$. On the contrary, Hossein Mohammadhosseini et. al [19] investigated the effect of adding polypropylene carpet fibers of length $30 \mathrm{~mm}$ on strength and transport properties of preplaced aggregate concrete. In this study, 20\% Palm oil fuel ash (POFA) was used as partial cement replacement. To inject the grout between the aggregates two methods were applied; gravity method and pumping method. It was found that for both methods addition of fibers increases tensile strength up to $0.75 \%$. They concluded this enhancement in tensile strength of PAFRC specimens up to maximum value might be due to arresting cracks in specimens by PP carpet fibers under indirect tension and beyond adding $0.75 \%$ fibers, the tensile strength decline because of the loss of fluidity as a result of higher fibers content, which in turn likely produced lower compaction degree. However, coated glass fibers are sometimes used in the research of glass fiber reinforced concrete such as Sabapathy Yogeeswaran Kanag et. al [20] studied the influence of epoxy coated E-glass fiber composites on the compressive and splitting tensile strengths of concrete. Likewise, Y.K. Sabapathy et. al [28] three grades of concrete M20, M30 and M40 and the varying fiber volume fractions $(0.5 \%, 1 \%$, $1.5 \%$ and $2 \%$ ) were used in this study. The results showed increase in fiber volume content increases the split-tensile strength for each grade of concrete. It was observed that approximately $10 \%$ to $20 \%$ of the total fibers across the crack section were perpendicular to the loading plane and all other fibers were distributed at different angles to the failure crack. To relate grade of concrete and percentage of fiber volume to strength properties the multiple regression analysis was done using the test results where the splitting tensile strength of concrete vary linearly with the addition of fibers. K.I.M Ibrahim [22] analyzed the effect of $18 \mathrm{~mm}$ long glass fiber in the mechanical properties of normal strength concrete at $0.1 \%, 0.3 \%, 0.5 \%$ volume fraction. Addition of $0.5 \%$ glass fiber exhibited an impressive result in splitting tensile strength which improved $94.8 \%$ strength in 28 days compared to control concrete. However, the tensile strength increased with the increase of fiber addition. Chaichannawatik
[23] et. al. used comparatively longer glass fiber of $35-40 \mathrm{~mm}$ with $0.013 \mathrm{~mm}$ diameter in normal strength concrete. Cylinder specimens (100 x 200 $\mathrm{mm}$ ) were formed for splitting tensile strength where $6 \mathrm{~kg} / \mathrm{m}^{3}$ fiber was mixed up. The study found that mixing of glass fiber increased the tensile $15 \%$ compared to the plain concrete. On the other hand, Loukil et. al. [24] showed that uniformly distributed short glass $(1 / \mathrm{d}=857)$ fiber in the concrete matrix created a macro homogeneity of the material which greatly influenced the tensile post-cracking parameters. The results showed that glass fiber with $3 \%$ weight fraction gained higher strength and dissipative energy capacity in tension compared to $2 \%$ glass fiber content and control concrete. Incorporation of glass fiber resisted the developing of cracks and microcracks and improved the bending capacity. Algburi et. al. [17] studied the effect of glass fiber and steel fiber on high performance reactive powder concrete (RPC). Glass fibers of 13 $\mathrm{mm}$ length with $1.3 \mathrm{~mm}$ diameter at $1.5 \%$ fiber content were used to prepare the glass fiber reinforced RPC (GFR-RPC). The result of the indirect tensile strength showed that glass fiber decreased the strength of reactive powder concrete which was $25 \%$ less than the non- fibrous reactive powder concrete (NF-RPC). The reason behind this problem was stated as the inadequate chemical treatment of fiber surface, which was important for making the surface texture structurally suitable to resist the tensile stress. Therefore, the weak bondage between the glass fiber and RPC matrix caused the breaking or slippage of fiber. Kushartomo et. at. [14] ran experiments on the mechanical behaviors of Reactive Powder Concrete reinforced with glass fiber and steel fiber. Results from the experiment indicated that splitting tensile strength of concrete specimens increased with the increment in glass fiber content. Increment in the flexural strengths was also observed with the addition of glass fiber content. Comparing the results obtained from glass fiber reinforced specimens to steel fiber reinforced specimens, it was observed that specimens reinforced with steel fibers showed higher strength behaviors in all aspects while tensile strength of steel fiber was 0.5 times compared to the tensile strength of glass fiber. Shivakumar et. al. [15] carried out an investigation on the mechanical properties of high strength concrete reinforced with metallic fiber and synthetic fiber. Results from the experiment showed that, increment in the tensile strength capacity was observed as inclusion of ARGF increased. Splitting tensile strength increased continuously reaching $63.215 \%$ increase at $1.2 \%$ fiber content compared to the $0 \%$ fiber content specimen. Also, flexural strength of fiber increased continuously up to $1.2 \%$ fiber content. Dehghan et. al. [21] explored the influence of recycled Glass Fiber Reinforced Polymer (GFRP) on splitting tensile 
strength in concrete. The result from this experiment showed significant increase in the tensile strength with the inclusion of virgin glass fiber. It was previously reported that usage of recycled GFRP causes reduction in workability [30]. Reduction in workability was overcome by preconditioning the recycled GFRP to a Saturated Surface Dry condition. Vandevyvere et. al. [25] conducted an experimental study on the influence of glass fibers as a reinforcing material on the mechanical behavior of concrete with recycled concrete aggregate. Results indicated that, tensile strength of glass fiber reinforced concrete increased with the addition of more glass fiber up to an optimum value. $0.5 \%$ dosage of fiber content was found as the optimum value. Flexural strength was also increased with the addition of $0.25 \%$ fiber. Fiber reinforced mixtures effectively controlled the formation of crack propagation. Crack Mouth Opening Distance (CMOD) which corresponds with the Limit of Proportionality (LOP) also increased with addition in fiber content and it was observed that higher fiber content allowed higher deformation before failure. Ali et. al. [31] experimented the behavior of mechanical properties of Normal Concrete Aggregate (NCA) and Recycled Concrete Aggregate (RCA) using glass fiber as reinforcing material. Results from the experiment showed that for both NCA and RCA, tensile strength increased with the addition in fiber content up to an optimum value which is $0.5 \%$ addition of fiber content by the volume of concrete. Though it didn't differ much but between NCA and RCA, tensile strength was higher for NCA with the similar amount of addition in fiber content. Taranu et. al. [32] conducted experiment on tensile behavior of glass fiber reinforced composite. The result from this experiment showed that use of five layers of glass fiber mesh which indicates $50 \%$ volume fraction dosage of fiber, gives the maximum tensile strength comparing with the other dosages of fiber mesh as well as un-reinforced specimen. Maximum corresponding strain decreased to 1.65 times lower with the addition of 5 layers of fiber mesh compared to the un-reinforced specimen. Five times increment in tensile elastic modulus was observed with the addition of single layer glass fiber mesh, but no further increment in tensile elastic modulus was observed with the addition of more fiber mesh. Ductility and young's modulus of mineral matrix improved significantly. Result and observation clearly revealed that the addition of maximum five layers of glass fiber mesh increased tensile strength capacity of mineral matrix composites. Hilles et. al [33] investigated the effects of Alkali-resistant glass fiber (AR-GF) in various contents on the mechanical behavior of High Strength Concrete (HSC). Results from the experiment showed that, increment in the tensile strength capacity was observed as inclusion of AR-GF increased. Splitting tensile strength increased continuously reaching $63.215 \%$ increase at $1.2 \%$ fiber content compared to the $0 \%$ fiber content specimen. Also, flexural strength of fiber increased continuously up to $1.2 \%$ fiber content. Overall, it was clearly seen that all the aspects of mechanical properties showed significant increment with the inclusion of AR-GF.

A summary of the tensile properties of concrete reinforced with synthetic fibers provided in Table 3

Table 3. Summarized data on Tensile properties of Synthetic Fibers

\begin{tabular}{|c|c|c|c|c|c|c|}
\hline \multicolumn{5}{|c|}{ Fiber } & \multirow[t]{2}{*}{ Tensile Properties (Effectiveness \%) } & \multirow[t]{2}{*}{ Reference } \\
\hline Name & $\begin{array}{l}\text { Length } \\
(\mathbf{m m})\end{array}$ & $\begin{array}{l}\text { Diameter } \\
(\mathbf{m m})\end{array}$ & $\mathrm{V} \%$ & Wt. & & \\
\hline Glass & $\begin{array}{l}40 \% 3,6 \\
+60 \% \\
12,20\end{array}$ & 0.014 & 0.3 & & $\begin{array}{l}\text { Tensile strength }=5.5 \mathrm{MPa}(+49.46 \%) \\
\text { Tensile strain }=0.000605(+505 \%)\end{array}$ & {$[18]$} \\
\hline $\begin{array}{l}\text { Epoxy } \\
\text { coated } \\
\text { e-glass }\end{array}$ & 30 & 1 & 2 & & $\begin{array}{l}\text { Tensile Strength }=3.63 \mathrm{MPa} \\
(+36.98 \%)\end{array}$ & {$[20]$} \\
\hline Glass & 18 & & 0.5 & & $\begin{array}{l}\text { Splitting tensile strength }=37.68 \mathrm{~kg} / \mathrm{cm}^{2} \\
(+94.8 \%)\end{array}$ & {$[22]$} \\
\hline Glass & 12 & 0.014 & 3 & $\begin{array}{c}66 \\
\mathrm{~kg} / \mathrm{m}^{3}\end{array}$ & $\begin{array}{l}\text { 3-point Flexural Tension Load }=15.86 \\
\mathrm{KN}(+61.8 \%)\end{array}$ & [24] \\
\hline
\end{tabular}




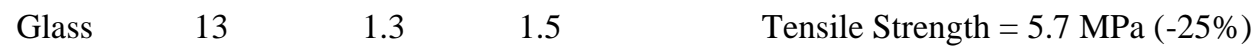

\begin{tabular}{|c|c|c|c|c|}
\hline $\begin{array}{l}\text { Polyvin } \\
\text { yl } \\
\text { alcohol }\end{array}$ & 12 & 0.039 & 1 & Tensile Strength $=3.8 \mathrm{MPa}(+18.8 \%$ \\
\hline $\begin{array}{l}\text { Multi- } \\
\text { filament } \\
\text { polypro } \\
\text { pylene } \\
\text { carpet } \\
\text { fiber }\end{array}$ & 30 & 0.448 & 0.75 & Tensile Strength $=4.85 \mathrm{MPa}(+31 \%)$ \\
\hline
\end{tabular}

[6] Zhang, Peng \& Han, Song \& Ng, Serina. (2018).

\section{CONCLUSION}

This comprehensive review presents the effect of different fiber and its type, properties on tensile properties of fiber reinforced concrete. The reports were reviewed and classified into subcategories depending on the fiber types (natural, metallic, synthetic). Based on the findings from this review, the main conclusions are as follows:

1. In general, the tensile strength of concrete can be enhanced by incorporating fibers into it as the presence of fibers across the failure plane resists propagation of cracks more effectively.

2. Since, the strength of fiber reinforced concrete is dependent on various factors such as the fiber shape, fiber length and aspect ratio, orientation of fibers, embedded length, and concrete properties, it is hard to estimate the generalized optimum fiber volume content for all aspects.

3. Comparatively, steel fiber reinforced concrete has better tensile strength than others. The combined effect of steel fibers stirrups further prevents the expansion and extension of the diagonal crack at the web.

\section{REFERENCES}

[1] Rilya Rumbayan, Meita Rumbayan, "A Study on The Utilization of Local Coconut Timber Waste as Sustainable Building Material", Proceeding of 5th International Exchange and Innovation Conference on Engineering \& Sciences (2019), pp. 1-3.

[2] Tamer Shubair et. al, "Investigate the Mechanical and Durability Properties of Cement Mortars being Exposed to Ammonium Nitrate Solutions", Proceeding of 2nd International Exchange and Innovation Conference on Engineering \& Sciences (2016), pp. 15-18.

[3] Smita Singh, Satish Gupta "Comparative Study of Glass Fiber Reinforced Concrete" International Journal of Research and Scientific Innovation (IJRSI) vol.5 issue 10, pp.30-33 October 2018

[4] P.K. Mehta, P.J.M. Monteiro, Concrete: Microstructure, Properties and Materials, third ed., McGraw-Hill, 2006.

[5] A. Bentur, S. Mindess, Fiber Reinforced Cementitious Composites, second ed., Taylor \& Francis, 2007.
Fiber-Reinforced Concrete with Application in Civil Engineering. Advances in Civil Engineering. 2018. 1-4. 10.1155/2018/1698905.

[7] F R Jones, 'Glass fibers', in High performance fibers, ed J W S Hearle, Cambridge, Woodhead Publishing, 2001, PP. 191-238.

[8] K.K. Chawla, Glass Fibers, Reference Module in Materials Science and Materials Engineering, Elsevier, 2016, ISBN 9780128035818

[9] Zakaria, Mohammad \& Ahmed, Mashud \& Hoque, Mozammel \& Islam, Shafiqul. (2016). Scope of using jute fiber for the reinforcement of concrete material. Textiles and Clothing Sustainability. 2. 10.1186/s40689-016-0022-5.

[10] Mohammad Zakaria, Mashud Ahmed, Mozammel Hoque \& Abu Shaid, A Comparative Study of the Mechanical Properties of Jute Fiber and Yarn Reinforced Concrete Composites, Journal of Natural Fibers. 17 (2020) 676-687.

[11] Kavitha, S., Effectiveness of bamboo fiber as an strength enhancer in concrete, International journal of earth science and engineering. 9 (2016) 192-196

[12] Majid Ali and Anthony Liu and Hou Sou and Nawawi Chouw, Mechanical and dynamic properties of coconut fibre reinforced concrete, Construction and Building Materials. 30 (2012) 814-825

[13] Yoo, D.-Y.; Shin, W. \& Chun, B., Corrosion effect on tensile behavior of ultra-high-performance concrete reinforced with straight steel fibers, Cement and Concrete Composites. 109 (2020) 103566

[14] Kushartomo, Widodo \& Ivan, Richard, Effect of Glass Fiber on Compressive, Flexural and Splitting Strength of Reactive Powder Concrete, MATEC Web Conf. 138 (2017) 03010.

[15] Sivakumar, A. \& Santhanam, M., Mechanical properties of high strength concrete reinforced with metallic and non-metallic fibres, Cement and Concrete Composites. 29 (2007) 603-608

[16] Aziminezhad, M.; Mardi, S.; Hajikarimi, P.; Moghadas Nejad, F. \& Gandomi, A. H., Loading rate effect on fracture behavior of fiber reinforced high strength concrete using a semi-circular bending test, Construction and Building Materials. 240 (2020) 117681 
[17] Algburi, A.H.M., Sheikh, M.N. \& Hadi, M.N.S. Mechanical properties of steel, glass, and hybrid fiber reinforced reactive powder concrete. Front. Struct. Civ. Eng. 13 (2019) 998-1006

[18] Kasagani, H. \& Rao, C., Effect of graded fibers on stress strain behavior of Glass Fiber Reinforced Concrete in tension, Construction and Building Materials. 183, (2018) $592-604$

[19] Mohammadhosseini, H.; Tahir, M. M.; Alaskar, A.; Alabduljabbar, H. \& Alyousef, R.,Enhancement of strength and transport properties of a novel preplaced aggregate fiber reinforced concrete by adding waste polypropylene carpet fibers, Journal of Building Engineering. 27 (2020) 101003

[20] Yogeeswaran Kanag, S., Anandan, Y. K., Vaidyanath, P., Baskar, P.: Strength properties of coated E-glass fibres in concrete, GRAĐEVINAR. 68 (2016) 9 697-703

[21] Dehghan, A.; Peterson, K. \& Shvarzman, A., Recycled glass fiber reinforced polymer additions to Portland cement concrete, Construction and Building Materials, 146 (2017) 238-250

[22] Ibrahim, K, Mechanical Properties of Glass Fiber Reinforced Concrete (GFRC), IOSR Journal of Mechanical and Civil Engineering. 13 (2016) 47-50

[23] Chaichannawatik B, Sirisonthi A, Hussain Q, Joyklad P, Mechanical Properties of Fiber Reinforced Concrete. AMM. 875 (2018) 174-178

[24] Marwa Loukil, Wiem Ben Hassine, Oualid Limam, Panagiotis Kotronis, Experimental determination of GFRC tensile parameters from three-point bending tests using an analytical damage model, Construction and Building Materials, Elsevier. 223 (2019) 477-490

[25] Vandevyvere, B.; Sierens, Z.; Verstrynge, E.; Vandewalle, L. \& Li, J., Effect of Glass Fibers on the Mechanical Behavior of Concrete with Recycled Concrete Aggregates (RCAs), IOP Conference Series: Earth and Environmental Science, 290 (2019) 012036

[26] M.A. Mansur, M.A. Aziz, A study of jute fiber reinforced cement composites, International Journal of Cement Composites and Lightweight Concrete, Volume 4, Issue 2, 1982, Pages 75-82, ISSN 02625075

[27] Zhao, J.; Liang, J.; Chu, L.; Shen, F. Experimental Study on Shear Behavior of Steel Fiber Reinforced Concrete Beams with High-Strength Reinforcement. Materials 2018, 11, 1682.

[28] Y. K. Sabapathy, S. Sabarish, C. N. A. Nithish et al., Experimental study on strength properties of aluminum fiber reinforced concrete, Journal of King Saud University - Engineering Sciences

[29] S. Anandaraj et al., Structural distress in glass fiber-reinforced concrete under loading and exposure to aggressive environments, Constr. Build. Mater. (2018)

[30] García, D., I. Vegas, and I. Cacho. "Mechanical recycling of GFRP waste as short-fiber reinforcements in microconcrete." Construction and Building Materials 64 (2014): 293-300.

[31] Ali, Babar, et al. "Influence of glass fibers on mechanical properties of concrete with recycled coarse aggregates." Civ. Eng. J 5.5 (2019): 1007 1019.

[32] Taranu, G.; Toma, I. O.; PLESU, R. \&

BUDESCU, M., Tensile behavior of glass fiber reinforced cement composite, Proceedings of the 4th International Conference on Advanced Materials and Systems, ICAMS 2012, 2012

[33] Hilles, M. M. \& Ziara, M. M., Mechanical behavior of high strength concrete reinforced with glass fiber, Engineering Science and Technology, an International Journal, 22 (2019) 920-928

[34] Liu, F.; Ding, W. \& Qiao, Y, Experimental investigation on the tensile behavior of hybrid steelPVA fiber reinforced concrete containing fly ash and slag powder, Construction and Building Materials, 241 (2020) 118000 